2013-02-26

\title{
Global environmental changes: setting priorities for Latin American coastal habitats.
}

Turra, A

http://hdl.handle.net/10026.1/1463

10.1111/gcb. 12186

Glob Chang Biol

Wiley

All content in PEARL is protected by copyright law. Author manuscripts are made available in accordance with publisher policies. Please cite only the published version using the details provided on the item record or document. In the absence of an open licence (e.g. Creative Commons), permissions for further reuse of content should be sought from the publisher or author. 


\title{
Global environmental changes: setting priorities for Latin American coastal habitats
}

\author{
ALEXANDERTURRA ${ }^{1}$, ALDO CR ÓQUER ${ }^{2}$, ALVAR CARRANZA $^{3}$, ANDR ÉS MANSILLA $^{4}$, \\ ARSENIO J. ARECES ${ }^{5}$, CAMILO WERLINGER ${ }^{6}$, CARLOS MART ÍNEZ-BAY ÓN ${ }^{5}$, \\ CRISTINA A.G. NASSAR ${ }^{7}$, ESTELA PLASTINO ${ }^{8}$, EVANGELINA SCHWINDT ${ }^{9}$, \\ FABRIZIO SCARABINO ${ }^{10}$, FUNGYI CHOW ${ }^{8}$, F ÉLIX L. FIGUEROA ${ }^{11}$, FL ÁVIO BERCHEZ ${ }^{8}$, \\ JASON M. HALL-SPENCER ${ }^{12}$, LUIS A. SOTO ${ }^{13}$, MARCOS S. BUCKERIDGE ${ }^{8}$, \\ MARGARETH S. COPERTINO ${ }^{14}$, MARIA TEREZA SZÉCHY ${ }^{15}$, \\ NATALIA GHILARDI-LOPES ${ }^{16}$, PAULO HORTA ${ }^{17}$, RICARDO COUTINHO ${ }^{18}$, \\ SIMONETTA FRASCHETTI ${ }^{19}$ and ZELINDA M. A. N. LE ÃO ${ }^{20}$ \\ ${ }^{1}$ Departamento de Oceanografia Biológica, Instituto Oceanográfico, Universiade de São Paulo, São Paulo, Brazil, ${ }^{2}$ Departamento de \\ Estudios Ambientales, Simon Bolivar University, Sartenejas, ${ }^{3}$ Polo de Desarrollo Universitario 'Grupo de Investigación \\ y formación de recursos humanos en biodiversidad' Centro Universitario Regional Este - CURE, Universidad de la República \\ Oriental del Uruguay, Sede Maldonado, Uruguay, ${ }^{4}$ Laboratorio de Macroalgas Antárticas y Subantárticas, Universidad de \\ Magallanes and Instituto de Ecología y Biodiversidad, Punta Arenas Chile, Instituto de Oceanologia, Universidade de La Habana, \\ Cuba, ${ }^{6}$ Facultad de Ciencias Naturales y Oceanograficas, Departamento de Oceanografia, Universidad de Concepcion, Concepcion, \\ Chile, ${ }^{7}$ Departamento de Botânica, Instituto de Biologia, Universidade Federal do Rio de Janeiro, Brazil, ${ }^{8}$ Departamento de \\ Botânica, Instituto de Biociências, Universidade de São Paulo, São Paulo, Brazil, ${ }^{9}$ Grupo de Ecología en Ambientes Costeros, \\ Centro Nacional Patagonico, Puerto Madryn, Argentina, ${ }^{10}$ Dirección Nacional de Recursos Acuático and Museo Nacional de \\ Historia Natural, Montevideo, Uruguay, ${ }^{11}$ Ecology Department, Faculty of Sciences, Málaga University, Málaga, Spain, ${ }^{12}$ Marine \\ Biology and Ecology Research Centre, University of Plymouth, Plymouth, UK, ${ }^{13}$ Instituto de Ciencias del Mar y Limnología, \\ Universidad Nacional Autónoma de México, México, ${ }^{14}$ Instituto de Oceanografia Universidade Federal do Rio Grande (FURG) Rio \\ Grande, Brazil, ${ }^{15}$ Departamento de Botânica, Universidade Federal do Rio de Janeiro, Brazil, ${ }^{16}$ Centro de Ciências Naturais e \\ Humanas, Universidade Federal do ABC, ${ }^{17}$ Departamento de Botânica, Centro de Ciências Biológicas, Universidade Federal de \\ Santa Catarina, Brazil, ${ }^{18}$ Instituto de Estudos do Mar Almirante Paulo Moreira, Arraial do Cabo, Brazil, ${ }^{19}$ Laboratory of Marine \\ Biology, Department of Biological and Environmental Science and Technologies, University of Salento, ${ }^{20}$ Departamento de \\ 1 Sedimentologia, Instituto de Geociências, Universidade Federal da Bahia, Brazil
}

\begin{abstract}
As the effects of the Global Climate Changes on the costal regions of Central and South Americas advance, there is proportionally little research being made to understand such impacts. This commentary puts forward a series of propositions of strategies to improve performance of Central and South American science and policy making in order to cope with the future impacts of the Global Climate Changes in their coastal habitats.
\end{abstract}

Keywords: benthic ecology, climate impacts, habitat mapping, long-term monitoring, marine biodiversity

Received 29 August 2012 and accepted 13 February 2013

The need for a science-policy agenda in Central and South America

The Intergovernmental Panel for Climate Change (IPCC) reports that Global Environmental Changes (GEC) are occurring quicker than at any other time over the last 25 million years and impacting upon marine environments (Bellard et al., 2012). There is overwhelming evidence showing that GEC are affecting both

Correspondence: Marcos S. Buckeridge, tel. ???, fax ???,

2 e-mail: msbuck@usp.br the quality and quantity of the goods and services provided by a wide range of marine ecosystems.

To discuss regional preparedness for global environmental changes, a workshop was held in Ilhabela, Brazil (22-26 April 2012) entitled 'Evaluating the Sensitivity of Central and South American Benthic Communities to Global Environmental Changes' that drew together scientists from ten Latin American and three European countries. Our analysis revealed critical knowledge gaps that hinder policy-making and assessments for the forthcoming IPCC Report (AR5, 2013-2014). We developed key recommendations on how to foster the

\begin{tabular}{|c|c|c|c|c|c|c|c|c|c|c|}
\hline \multirow{2}{*}{2} & $\mathbf{G}$ & $\mathbf{C}$ & 1 & 2 & 1 & 8 & \multirow{2}{*}{$\mathbf{B}$} & \multirow{2}{*}{$\begin{array}{c}\text { Dispatch: } 6.3 .13 \\
\text { Author Received: }\end{array}$} & \multirow{2}{*}{$\frac{\text { Journal: GCB }}{\text { No. of pages: } 5}$} & \multirow{2}{*}{\begin{tabular}{|l} 
CE: Sangeetha \\
PE: Eswari
\end{tabular}} \\
\hline & Journal & 1 Name & & Iant & Iscrip & te. & & & & \\
\hline
\end{tabular}


development of a regional science-policy agenda to meet urgent demand for sound scientific advice in the face of rapid changes to marine coastal ecosystems in Latin America.

\section{Threats to ecologically and socio-economically important coastal habitats in Latin America}

Central and South America is the home of $1 / 3$ of the world's most biodiverse countries, and is one of the most urbanized regions in the world (Unep, 2011). Besides regional heterogeneity, and significant variation in size and economic development, the 33 countries of the region have relatively young democracies that face a number of common political, social-economic, environmental, and science-policy issues. The marine habitats are of fundamental importance for the approximately 610 million coastal residents, but the need to develop sustainable coastal management occurs at a time of rapidly changing climate coupled with social upheaval such as uncontrolled urbanization and social inequality.

Latin America marine realms include a wide range of benthic ecosystems, many of which are unique and constitute hotspots of biodiversity (Miloslavich et al., 2011). These include the kelp forests on the Cape Horn Biosphere Reserve (Fig. 1; Rozzi et al., 2012), the huge rhodolith beds along the Tropical Southwestern Atlantic coast (Berchez et al., 2009; Amado-Filho et al., 2012), the large blue carbon ecosystems, formed by tropical mangroves and seagrass beds (Copertino, 2011)and the highly biodiverse coral reefs of the Tropical Atlantic, with their large number of endemic species (Leão et al., 2003). Therefore, major efforts to protect these marine

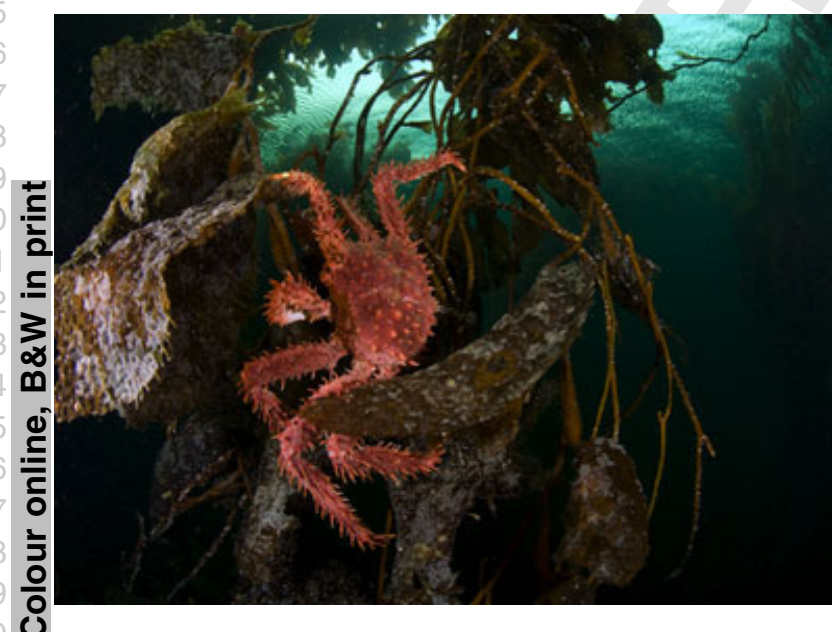

Fig. 1 A kelp forest in the Cape Horn Biosphere Reserve, Chile. This habitat is extremely important as a $\mathrm{CO}_{2}$ sink and for fisheries. Centolla crab Lithodes santolla growing on Macrocystis pyrifera at the Capitan Aracena Island, Magallanes (Photo: Mathias Hüne). habitats are essential. Fundamental regional economic activities, such as fisheries, with the world's highest average annual growth in the period 1970-2008 (21.1\% as reported by Salas et al., 2011), and tourism, with an 8.6-13.9\% total contribution to gross domestic product (Wttc, 2012), depend on marine environmental quality.

Multiple human impacts endanger Latin America coastal habitats. Changes in the composition and distribution of sensitive habitats are already occurring (Martins et al., 2012), with highly impacted sites in the Eastern Caribbean, and medium to highly impacted zones around almost the entire continent (Halpern et al., 2008). Without timely action the situation will steadily deteriorate. Bleaching and diseases in coral reefs (Fig. 2), both linked to ocean warming, are becoming an increasing problem (Wilkinson \& Souter, 2008). Kelp forests have proven to be highly susceptible to temperature and current changes (Wernberg et al., 2011) and ocean acidification not only threatens to degrade the world's largest rhodolith beds along the Brazilian coast (Amado-Filho et al., 2012) but also to seriously reduce the ability of edible shellfish, such as mussels and oysters, to produce shells, thereby threatening local aquaculture activities and food security. Extreme events, such as cyclones, are occurring with greater frequency (Emanuel, 2005), thereby impacting coastal habitats, with particular severity in the SE Atlantic coast. Moreover, harmful algal blooms, partially related to temperature increase, have negative impacts on the quality of coastal areas as a whole.

\section{Gaps in scientific knowledge}

Concerted efforts to understand the effects of GEC on Latin America coastal habitats lag behind other regions

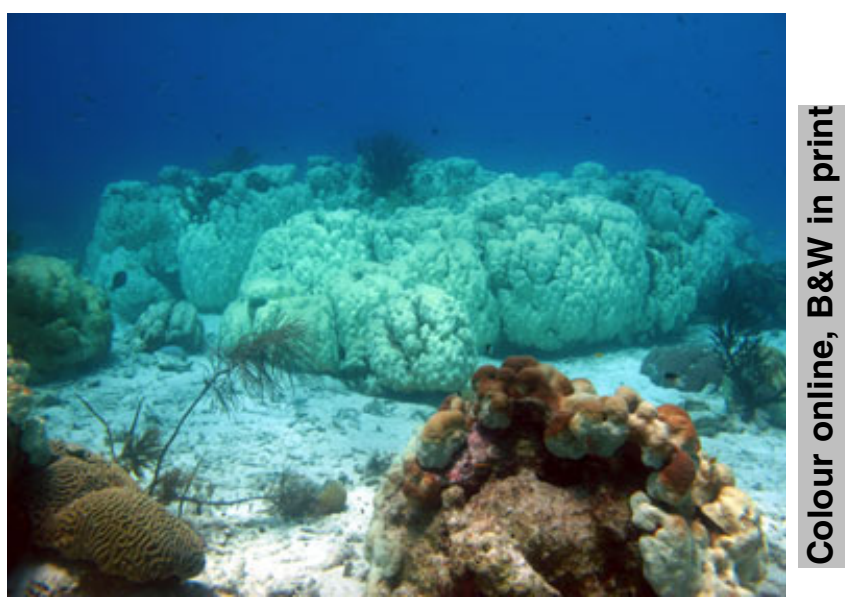

Fig. 2 A coral bleaching event. Bleaching events in the Caribbean Sea are becoming more frequent and severe (Photo: Aldo Croquer). 
worldwide, leaving society ill-prepared to cope with future changes. The paucity of time-series data in the southern hemisphere is especially acute in developing countries (Rosenzweig et al., 2008). Less than $5 \%$ of the participants in the Second International Symposium on the Effects of Climate Change on the World's Oceans (Korea, May 2012) were from C\&SA, exemplifying the low priority afforded to the issue in the regional scientific agenda. In short, baseline, monitoring and detailed forecast studies are insufficient for a specific understanding of detrimental GEC effects in the region. This has arisen due to a lack of scientific incentives and a dearth of efforts at the science-policy interface across the entire Latin America region.

\section{Baselines}

Integrated baseline studies are required to assess seabed-habitat distribution and quality, as well as human threats and risks associated with local and regional climate change scenarios. National support, within a multinational strategy, will be essential for systematic habitat mapping that should include geomorphological and ecological features at different spatial scales, using standardized approaches, to facilitate spatial and temporal comparisons, as well as the organization and dissemination of information. This will allow identification of biodiversity hot-spots, habitats of high value in terms of ecosystem services, and areas most vulnerable and less resilient to local anthropogenic impacts and GEC. It is imperative to take into account the potential synergies deriving from the interaction of multistressors, as the effects of GEC will differ according to the different combinations of threats. This information would also be important as a base for marine spatial planning strategies. For this issue, efforts should be targeted to the less studied ecosystems and regions, such as the Cape Horn Biosphere Reserve and the Brazilian rhodolith beds.

\section{Monitoring}

A strategic array of physical and biological monitoring stations is an urgent requirement in C\&SA, to fill critical knowledge-gaps, and provide an early warning system of GEC on coastal communities. The systematic application of monitoring protocols to each habitat, scale, and level of organization, as well as to the various oceanographic conditions, is essential for documenting habitat degradation, carbon sinks, the reduction of primary and secondary production, and habitat destruction, fragmentation or loss, as well as biological invasion, and regime shifts. Thus, support for longterm time-series data collection through national and international networks is required using rigorous standardized protocols. The Monitoring Network for Coastal Benthic Habitats (ReBentos), to date one of the main extensive networks implemented in Latin America for monitoring marine habitats, groups together around 100 researchers starting to apply standardized protocols to both soft and hard substrata, viz., rocky shores, coral reefs, rhodolith beds, mangroves, salt marshes, estuaries, and sandy beaches, at stations distributed all along the Brazilian Coast. The South American Research Group for Coastal Ecosystems (SARCE), comprising 108 sampling localities, is another example. Efforts should be made to spread these tried and tested schemes to other countries in the region, through combining procedures and efforts with local projects already under way, and building an open access data-base to provide information for local, regional, and global habitat health evaluation and forecasts, this including the Regular Process of the United Nations for Global Reporting and Assessment of the State of the Marine Environment. Initial efforts should be centered on locations already undergoing immediate damaging pressures, such as the Caribbean Coral Reefs, the SE Atlantic rocky shores, or the southernmost kelp forests.

\section{Forecasts}

The absence of baseline studies seriously compromises reliable forecasting in Latin America. There is an urgent need to refining regional and local scenarios of threats related to GEC, to assess the uncertainties, risks, and thresholds at organism and ecosystem levels. Not only the identification and quantification of carbon sinks and cycling processes but also experimental and modeling approaches, are key challenges to forecasting future changes.

\section{A scientific-support policy}

The challenges are so great that collaborative efforts among institutions at national and international levels are essential. Most of the present initiatives in Latin America are national, for example, Brazilian Network for Blobal Climate Changes (Rede CLIMA), or bilateral, for example, the CNPq-CONICET Brazil \& Argentina funding support. Efforts should be centered on networking the knowledge-base across disciplines and among all Latin American countries. Besides strengthening the support of national science funding agencies to studies focused on GEC, multilateral international agreements are also required. The incentive of capacitybuilding efforts at undergraduate and graduate levels, and of habitat mapping and the evaluation of GEC effects, is mandatory, as is stimulation of the formation 
and recruitment of interdisciplinary capacities in marine and human sciences, and technology, at a continental level. There is also a need to stimulate a better and wider communication of GEC to society as a whole, through innovative educational approaches and efficient scientific-outreach efforts, with focus on the Latin American marine environments, which, by leading to greater public involvement, could thus increase political interest.

\section{Political and governance issues}

Urgency requires the immediate establishment of a collaborative framework, to so induce a systematic and integrated spatial planning process for the sustainable use of marine biodiversity and other resources in C\&SA. This would include joint efforts to identify and give precedence to the most pressing issues related to GEC and coastal habitats. There is the need for a more pro-active engagement of Latin American governments and sector-ministries, as well as the recruitment of socio-economic stakeholders, in a co-management effort regarding GEC and sustainable development, with a more evident focus on the sea. The delimitation of marine protected areas to reach the $10 \%$ goals established during the COP-10 - Convention of Biological Diversity - is a priority. Even in Brazil, the most protected country of the region (Halpern et al., 2012), only $1.5 \%$ of the exclusive economic zone is protected and nearly $9 \%$ of priority areas for marine conservation have already been ceded to oil companies for offshore exploitation (Scarano et al., 2012). The establishment of national councils, such as the Brazilian Inter-ministry Commission for Marine Resources, or processes, such as the National Science, Technology and Innovation Conferences in Brazil, could be considered as models to be followed. Initiatives should emerge as political efforts, under the responsibility of those countries already undertaking successful experiences, or those in better economic conditions, such as Argentina, Brazil, Chile, and Mexico. International articulation efforts should be reinforced by establishing formal mandates and securing resources for leadership institutions and initiatives, such as the Intergovernmental Oceanographic Commission at UNESCO, to consolidate South-to-North, and significantly increase South-to-South collaboration, thereby also benefiting other areas, such as Africa, India, and Southeast Asia.

\section{Science and policy-making under an integrated perspective}

Nations should improve communication between policy makers and scientists, to the point that new policies can be based on the best available evidence, and scientific studies widened to include the most policy-relevant questions. The UN Regular Process, IPCC, IPBES (Intergovernmental Science-Policy Platform on Biodiversity and Ecosystem Services), and the Future Earth initiatives should be considered as opportunities for the international integration of this agenda. Finally, once both IPBES and IPCC undertake the regular and timely assessment of knowledge, thereby identifying and giving precedence to the key scientific information needed for policymakers, priority on issues regarding climate change in the IPBES agenda, and those on marine habitats, biodiversity, and ecosystem services in the IPCC, becomes mandatory.

\section{Operational agenda for the near future}

As it is impossible to address all the issues simultaneously, multicriteria analysis becomes necessary. This would include the survey and analysis of existing data, to thus facilitate the identification of priorities for urgent action. Our main recommendations include sensitivity analysis on an eco-regional scale, thence addressing vulnerability to GEC on a habitat basis. This would include ecological (e.g., geographical distribution and associated biodiversity) and socio-economic (e.g., the economic evaluation of ecosystem goods and services) aspects. Local forecasting, based on the downscaling of available GEC scenarios, geographical distribution, conservation status, and the likely response of different habitats in different eco-regions, as well as the evaluation of potential ecological and socio-economic impacts should be a first step. Once having established the geographical scope of priority issues, both scientists and policy-makers should work together, by searching for the most effective governance setting to design and implement adaptation and/or mitigation schedules, either at international, national, or local levels.

\section{Acknowledgements}

Supported by FAPESP (2011/22074-0) and ReBentos (CNPq/ FAPESP). English revision by Ramon Arthur Clark. Authors thank the comments on the manuscript made by the colleague Fabio Scarano (The Nature Conservancy).

\section{References}

Amado-Filho GM, Moura RL, Bastos AC et al. (2012) Rhodolith beds are major $\mathrm{CaCO} 3$ bio-factories in the tropical South West Atlantic. PLoS ONE, 7, e35171.

Bellard C, Bertelsmeier C, Leadley P, Thuiller W, Courchamp F (2012) Effects of climate change on the future of biodiversity. Ecology Letters, 15, 365-377.

Berchez FAS, Tiago CG, Rosso S, Dias G, Oliveira EC (2009) Structure of a coralline algal bed on southeastern Brazil. Brazilian Journal of Ecology, 13, 49-57.

Copertino MS (2011) Add coastal vegetation to the climate critical list. Nature, 473, 255. 
Emanuel K (2005) Increasing destructiveness of tropical cyclones over the past 30 years. Nature, 436, 686-688.

Halpern BS, Walbridge S, Selkoe KA et al. (2008) Global map of human impact on marine ecosystems. Science, 319, 948-952.

Halpern BS, Longo C, Hardy D et al. (2012) An index to assess the health and benefits of the global ocean. Nature, 488, 615-620.

Leão ZMAN, Kikuchi RKP, Testa V (2003) Corals and coral reefs of Brazil. Latin American Coral Reefs, 13, 9-52.

Martins CDL, Arantes N, Faveri C et al. (2012) The impact of coastal urbanization on the structure of phytobenthic communities in southern Brazil. Marine Pollution Bulletin, 64, 772-778.

Miloslavich P, Klein E, Díaz JM et al. (2011) Marine biodiversity in the Atlantic and Pacific Coasts of South America: knowledge and gaps. PLoS ONE, 6, e14631.

Rosenzweig C, Karoly D, Vicarelli M et al. (2008) Attributing physical and biological impacts to anthropogenic climate change. Nature, 453, 353-357.
Rozzi R, Armesto JJ, Gutiérrez JR et al. (2012) Integrating ecology and environmental ethics: Earth stewardship in the southern end of the Americas. BioScience, 62, 226-236.

Salas S, Chuenpagdee R, Charles A, Seijo JC (eds) (2011) Coastal Fisheries of Latin America and the Caribbean, ???, Rome.

Scarano F, Guimarães A, Silva JMD (2012) Rio+20: Lead by example. Nature, 486 25-26.

Unep (ed.) (2011) Annual Report 2010: A Year in Review. United Nations Environment Programme, Nairobi.

Wernberg T, Russell BD, Moore PJ et al. (2011) Impacts of climate change in a global hotspot for temperate marine biodiversity and ocean warming. Journal of Experimental Marine Biology and Ecology, 400, 7-16.

Wilkinson C, Souter D (eds.) (2008) Status of Caribbean Coral Reefs After Bleaching and Hurricanes in 2005. GCRMN, Townsville.

Wttc (ed.) (2012) Travel \& Tourism Economic Impact 2012-Caribbean, World Travel \& Tourism Council, London. 


\section{Author Query Form}

\section{Journal: $\quad$ GCB}

Article: $\quad 12186$

Dear Author,

During the copy-editing of your paper, the following queries arose. Please respond to these by marking up your proofs with the necessary changes/additions. Please write your answers on the query sheet if there is insufficient space on the page proofs. Please write clearly and follow the conventions shown on the attached corrections sheet. If returning the proof by fax do not write too close to the paper's edge. Please remember that illegible mark-ups may delay publication.

Many thanks for your assistance.

\begin{tabular}{|l|l|l|}
\hline Query reference & Query & Remarks \\
\hline 1 & $\begin{array}{l}\text { AUTHOR: Please provide full address } \\
\text { details for all affiliations. }\end{array}$ & $\begin{array}{l}\text { AUTHOR: Please provide telephone } \\
\text { number and fax number for correspond- } \\
\text { ing author. }\end{array}$ \\
\hline 2 & $\begin{array}{l}\text { AUTHOR: Please provide the publisher } \\
\text { name for reference Salas et al. (2011). }\end{array}$ & \\
\hline 3
\end{tabular}


Required software to e-Annotate PDFs: Adobe Acrobat Professional or Adobe Reader (version 7.0 or above). (Note that this document uses screenshots from Adobe Reader $\mathrm{X}$ )

The latest version of Acrobat Reader can be downloaded for free at: http://get.adobe.com/uk/readerl

Once you have Acrobat Reader open on your computer, click on the Comment tab at the right of the toolbar:

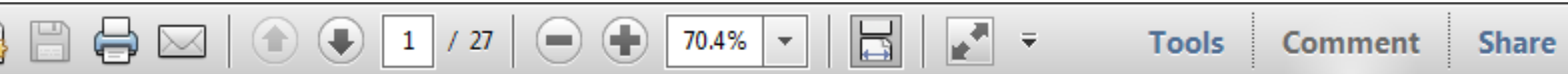

This will open up a panel down the right side of the document. The majority of tools you will use for annotating your proof will be in the Annotations section, pictured opposite. We've picked out some of these tools below:

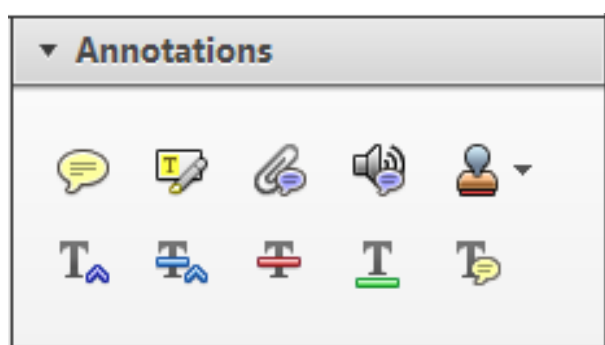

1. Replace (Ins) Tool - for replacing text.

Strikes a line through text and opens up a text box where replacement text can be entered.

How to use it

- Highlight a word or sentence.

- Click on the Replace (Ins) icon in the Annotations section.

- Type the replacement text into the blue box that appears.

Idard tramework for the analysis of $\mathrm{m}$ icy-Nevertheless, it also led to exog،

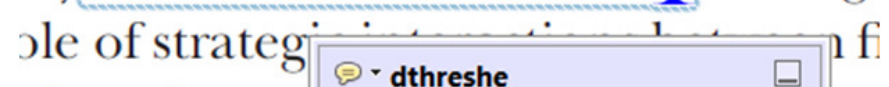
aber of comp 08/06/2011 15:58:17 is that the $\mathrm { s } 1 \longdiv { \text { , which led } }$ of nain compo: be level, are exc nc

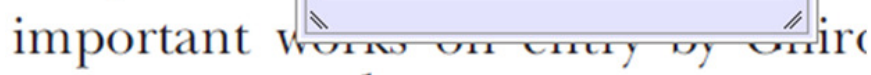
M henceforth) ${ }^{1}$ we snen the "hlark $\mathrm{h}$

3. Add note to text Tool - for highlighting a section to be changed to bold or italic.

Th Highlights text in yellow and opens up a text box where comments can be entered.

How to use it

- Highlight the relevant section of text.

- Click on the Add note to text icon in the Annotations section.

- Type instruction on what should be changed regarding the text into the yellow box that appears.

namic responses of mark ups ent with the VAR evidence

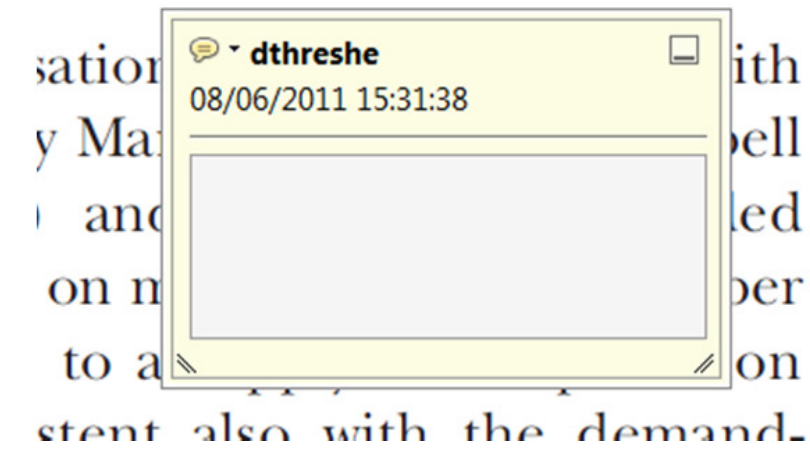

2. Strikethrough (Del) Tool - for deleting text.

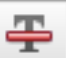

Strikes a red line through text that is to be deleted.

How to use it

- Highlight a word or sentence.

- Click on the Strikethrough (Del) icon in the Annotations section.

there is no room tor extra prohts al s ups are zero and the number of ret) values are not determined by Blanchard and Kiyotaki (1987), sfect competition in general equilil ts of aggregate demand and supply lassical framework assuming monol eon an evorenous number of firme

4. Add sticky note Tool - for making notes at specific points in the text.

Marks a point in the proof where a comment needs to be highlighted.

How to use it

- Click on the Add sticky note icon in the Annotations section.

- Click at the point in the proof where the comment should be inserted.

- Type the comment into the yellow box that appears.

iaisu airu suppiy sirucks. hivsl ui

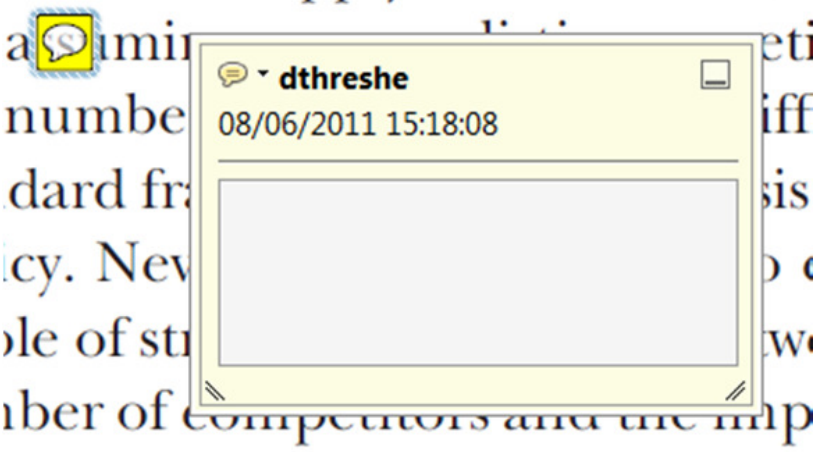

is that the structure of the sects. 
5. Attach File Tool - for inserting large amounts of text or replacement figures.

Inserts an icon linking to the attached file in the appropriate pace in the text.

How to use it

- Click on the Attach File icon in the Annotations section.

- Click on the proof to where you'd like the attached file to be linked.

- Select the file to be attached from your computer or network.

- Select the colour and type of icon that will appear in the proof. Click OK.

E N D

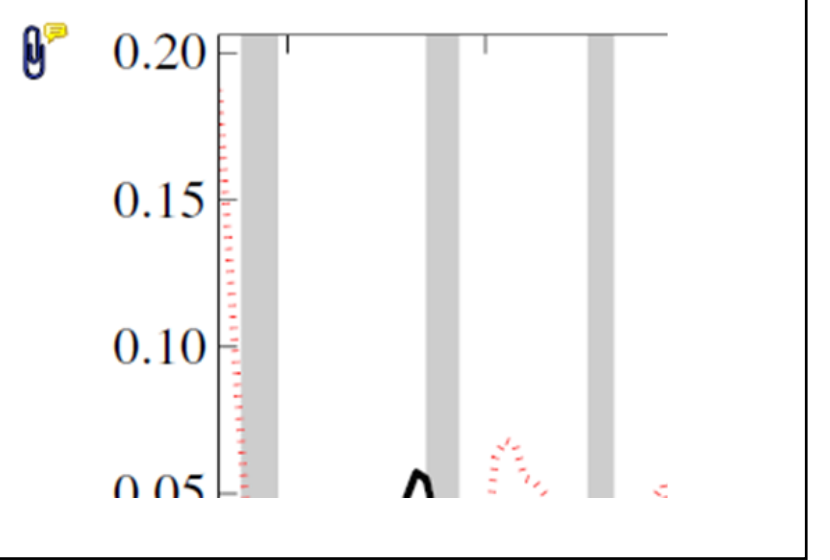

6. Add stamp Tool - for approving a proof if no corrections are required.

- Inserts a selected stamp onto an appropriate place in the proof.

\section{How to use it}

- $\quad$ Click on the Add stamp icon in the Annotations section.

- Select the stamp you want to use. (The Approved stamp is usually available directly in the menu that appears).

- Click on the proof where you'd like the stamp to appear. (Where a proof is to be approved as it is, this would normally be on the first page).

ot the business cycie, starting with the on perfect competition, constant ret

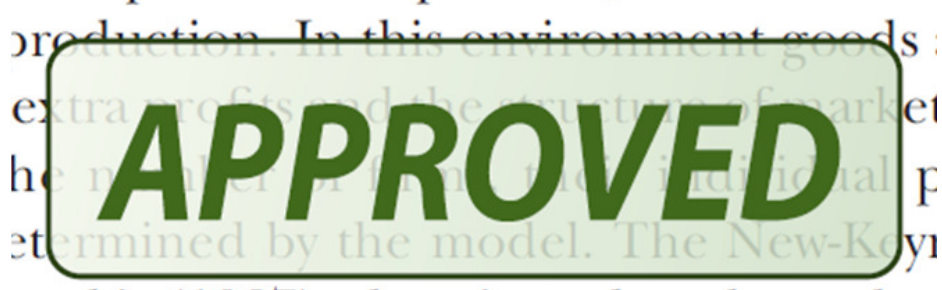
otaki (1987), has introduced produc general equilibrium models with nomin:

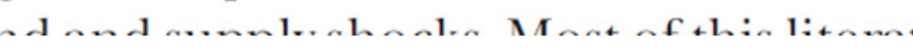

- Drawing Markups

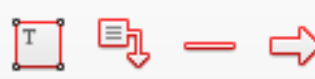

$0 \bigcirc \sqrt{6} \otimes$

\section{How to use it}

- Click on one of the shapes in the Drawing Markups section.

- Click on the proof at the relevant point and draw the selected shape with the cursor.

- To add a comment to the drawn shape, move the cursor over the shape until an arrowhead appears.

- Double click on the shape and type any text in the red box that appears.
7. Drawing Markups Tools - for drawing shapes, lines and freeform annotations on proofs and commenting on these marks.

Allows shapes, lines and freeform annotations to be drawn on proofs and for comment to be made on these marks..

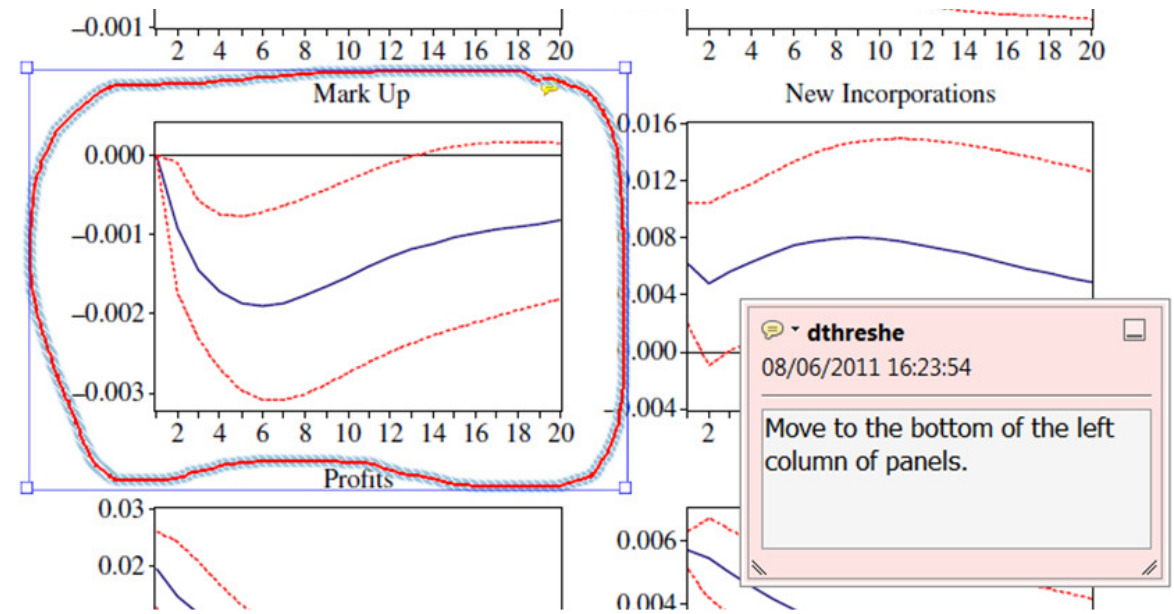

For further information on how to annotate proofs, click on the Help menu to reveal a list of further options:

\begin{tabular}{|l|l|l|l|l|l|l|}
\hline File ecoj_2384_CrxRev2_EV_19-Jul-10.pdf - Adobe Reader & Edit View Window \\
\hline
\end{tabular}

